\title{
Role of Physical Attractiveness in Mate Selection by Educated Women in Khyber Pakhtunkhwa
}

Saima Sarir ${ }^{1}$, Niaz Muhammad ${ }^{2}$, Intikhab Ala ${ }^{3}$, Mushtaq Ahmad Jadoo ${ }^{4}$, Shahid Iqbal ${ }^{5}$, Sudhair Abbas ${ }^{5}$, Abdul Sajid ${ }^{6 *}$ and Natasha Kashif $^{6}$

${ }^{1}$ Department of Rural Sociology, The University of Agriculture, Peshawar, Pakistan

${ }^{2}$ Department of Sociology, University of Peshawar, Pakistan

${ }^{3}$ Department of Rural Sociology, Faculty of Rural Social Sciences, The University of Agriculture, Peshawar, Pakistan

${ }^{4}$ Department of Rural Sociology, University of Peshawar, Pakistan

${ }^{5}$ Sarhad university of Science and Information Technology, Peshawar, Pakistan

${ }^{6}$ College of Veterinary Sciences and Animal Husbandry, Abdul Wali Khan University, Garden Campus, Mardan, Pakistan

\begin{abstract}
The present study was conducted to probe the role of physical attractiveness in mate selection among educated females of Khyber Pakhtunkhwa. Data for the study were collected through pre-tested questionnaire from 278 sampled working women from three public sector universities in Khyber Pakhtunkhwa i.e. The University of Agriculture, University of Peshawar and Shaheed Benazir Bhutto Women University Peshawar. Results reveal that the females principally preferred well dressed, tall, broad shoulder, clean shaved, fair colored and physically attractive males with the same age and living in nuclear families. At the same time, there was a strong tendency of females towards westernization and materialistic values regarding mate selection. Despite emphasizing on physical characteristics, the females were also less concerned about physical appearance. A very large majority preferred economically sound intelligent man who have good job. The study recommends that an awareness campaign through mass media, religious leaders, civil society and political parties' needs to launch to inform both the educated and uneducated females and their parents about the nature and impact of religious misinterpretations, western values, materialistic outlook and idealism affected the mate selection decision mainly.
\end{abstract}

Keywords: Physical attractiveness; Mate selection; Education

\section{Introduction}

Mate selection is one of the most important decisions in a person's life. It is not a simple but complex phenomenon for every male and female. Before they move for the act of marriage, both have different considerations. The process of mate selection in fact consists of a series of steps where decision regarding mate is made through external characteristics such as appearance, social class or manners, attitude, beliefs and common values [1]. Other factors determining mate selection include paternal and maternal preferences that predominantly prevailed more in traditional societies. However, for many people today, romance is now an important determinant in selecting a life partner [25]. Though variations in mate selection do exist in various societies; the main philosophy is the reproduction, continuity of family name as explicit elements while sex satisfaction as implicit in nature. Human physical considerations such as age, bravery, beauty are some additional influencing factors [6].

Mate selection, rather getting married in Pakistani context, has been widely perceived a matter of extreme significance in Pakistanis' lives. It is not just an agreement between two partners but an exercise which involves religion and culture as well. The decisions of parents and other family members are considered highly important in this regard. The mate selection yardsticks differ from family to family based on their unique way of thinking (Gulzar and Husain) however, physical characteristics or facial attractiveness is an integral part of aesthetic preference needed to select a mate of life in all societies of the world including Pakistan [7,8]. Perilloux et al. [9] found physical attractiveness and being socio-economically stable are the top priorities worldwide. Bronstad, Russel, Rhodes et al. and Winkielman et.al report face as a unique social stimulus in interaction with the potential mate [10-12]. It provides a ray of information about the gender, race and emotions of the potential mate. The major feature in fact attracts and influences the opposite sex is facial attractiveness prevalent across the groups, cultures and society as a whole. For Hoppe et al. and Fisman et al., men and women when choosing life partners tend to go by physical qualities especially men give more importance to physical attractiveness $[13,14]$.

Physical qualities like age, height and weight are important for both males and females. A slight difference in this respect is men favor young and thin females compared to women who like liked young and tall males. It is also agreed that physical qualities were more easily observable compared to education and occupation of the potential mate [15]. Similarly, Belot and Francesconi found women preferring young, tall and physically attractive males [16]. Berry and Miller state attractiveness as an independent predictor of mate relationship where more attractive women were interacted more than the less attractive women [17]. Women attractiveness was again not only counted as an important criterion for their personality but good predictor of quality of interaction among the potential couples. Females on the other hand, prefer those men who have higher socioeconomic status orare prosperous and older than them $[9,18,19]$.The other major considerations of females are men intelligence, ambitions and potential for successful life along with the personal characteristics such as kindness, understanding, experiences and openness [20].

*Corresponding author: Abdul Sajid, College of Veterinary Sciences and Animal Husbandry, Abdul Wali Khan University, Garden Campus, Mardan, Pakistan, Tel: +92 937 9230640; E-mail: sajidvet137@awkum.edu.pk

Received January 29, 2018; Accepted February 07, 2018; Published February 13, 2018

Citation: Sarir S, Muhammad N, Ala I, Jadoo MA, lqbal S, et al. (2018) Role of Physical Attractiveness in Mate Selection by Educated Women in Khyber Pakhtunkhwa. Arts Social Sci J 9: 335. doi: 10.4172/2151-6200.1000335

Copyright: (C) 2018 Sarir S, et al. This is an open-access article distributed unde the terms of the Creative Commons Attribution License, which permits unrestricted use, distribution, and reproduction in any medium, provided the original author and source are credited. 


\section{Research Methodology}

The present study explores the role of physical attractiveness in mate selection in Khyber Pakhtunkhwa. The data for the study were collected from three educational institutions i.e. University of Peshawar, the University of Agriculture, Peshawar and Shaheed Benazir Bhutto Women University, Peshawar. According to official record of the three institutions, there were 661 educated female employees with a break up of 242, 85 and 214 respectively. The main reason of the selection of the three institutions was getting information from females belonging to diverse areas, environment and cultures. Data were collected from female teachers and females working on different posts in the selected universities. Though a large sample size gives better results but due to time and human resource constraints, a total of 278 sampled respondents were selected for data collection through sampling procedure designed by Sekaran [21]. The sample size within each educational institution was determined through the proportional sampling method. However, the samples from each of the selected area were picked through lottery method of simple random sampling.

The study was based on both the primary and secondary data. Primary data were obtained through a pretested questionnaire which was developed on the basis of study objectives, research questions, conceptual framework and other required information. A team of three investigators was hired and trained on the questionnaire. All the important sections of the tools of data collection were thoroughly discussed with the intention to obtain accurate and quality data. The whole task of data collection was carefully monitored by the researcher herself and this exercise took about 03 months.

After collection, the data was edited and entered into computer. The data was processed and analyzed through SPSS where the basic results were drawn through frequencies and percentages. Further, in order to assess the association between the dependent variable and independent variables, Chi -Square and Fisher Exact tests were also used.

\section{Results and Discussion}

This section describes the results after the analysis of data. It starts with the description of the perception of sampled respondents about physical characteristics in connection with selecting mate for marriage and followed by measuring the association between the dependent variable i.e. the mate selection with the independent variable i.e. the physical characteristics.

\section{Physical Characteristics of Mate}

In connection with the perception of sampled females about the physical characteristics of mate, Table 1 describes that 83.1 percent each of the selected females stated 'yes' to the statement that beauty is a relative term and varies from person to person in mate selection but the male's personality traits are important element in mate selection. A 71.9 percent in this connection stated yes again to the statement that females nowadays prefer well-dressed males The results are similar with the findings of Buss who asked people what aspects they would rate how important are the qualities of physical attractiveness among them in relation females [22]. Men gave pointedly higher ratings to the importance of attractiveness than did women in 34 out of 37 countries studied. The same is the case found by Buss and Barnes [23].

In connection with the physical features of the potential or probable mate, Table 1 further states that a 79.1 percent of the sampled females again validated again that mate should at least be good looking. Another 62.2, 47.5 and 40.6 percent of the females preferred tall and broad shoulder males, who have fair color and are clean shaved. A 39.6 and 37.8 percent at the same time negated the statements giving preference to fair color and clean shaved men respectively. These findings are in line with the findings of Kurzban and Weeden [14,15].

On the other hand, for 47.5 percent of the selected females, physical features of males nowadays are less important. A 66.5 percent of the females preferred males' intelligence over their physical attractiveness. A 77.4 percent in this regard favored mates who have good job or sound economic background. A 60.1 percent of the females were even were not willing to marry with not good looking males. These results are in line with the studies conducted by Hatfield and Sprecher [20] called physical features of males nowadays are less important followed by previous studies [15,24-27] who found people prefer partners of higher status, good job, high education, and occupation having professional edge and skillful background. At the same time, Buunk et aland Kenrick et al report females were also willing to marry a male who is not good looking [18,28].

Table as whole reveals physical attractiveness as the major consideration of females in mate selection. At the same time, there was contradiction in the perception and actions of the females. On one hand, they emphasized on physical features of the males such as good looking, well dressed and cleaned shaved males whereas on the other hand, they gave more weightage to male intelligence, good job and sound economic background over physical attractiveness in mate selection (Table 1).

\section{Association between Physical Characteristic and Mate Selection}

To describe the association between mate selection and physical characteristics of the mate, Table 1 reports a significant association of dependent variable i.e., mate selection with independent variable i.e.

\begin{tabular}{|c|c|c|c|c|}
\hline S. No. & Physical Characteristics & Yes & No & Uncertain \\
\hline 1. & Beauty is a relative term and varies from person to person & $231(83.1)$ & $34(12.2)$ & $13(4.7)$ \\
\hline 2. & Males personality traits are important element in mate selection & $231(83.1)$ & $37(13.3)$ & $10(3.6)$ \\
\hline 3. & Females nowadays, prefer well-dressed males & $200(71.9)$ & $44(15.8)$ & $34(12.2)$ \\
\hline 4. & You prefer tall and broad shoulder males & $173(62.2)$ & $69(24.8)$ & $36(12.9)$ \\
\hline 5. & Your mate should at least be good looking & $220(79.1)$ & $39(14.0)$ & $19(6.8)$ \\
\hline 6. & Physical features of males nowadays are less important & $132(47.5)$ & $116(41.7)$ & $30(10.8)$ \\
\hline 7. & You like to marry with a clean shave male & $113(40.6)$ & $105(37.8)$ & $60(21.6)$ \\
\hline 8. & You prefer fair color males & $132(47.5)$ & $110(39.6)$ & $36(12.9)$ \\
\hline 9. & You prefer male's intelligence beyond his physical attractiveness & $185(66.5)$ & $84(30.2)$ & $9(3.2)$ \\
\hline 10. & You are willing to marry with a male who is not good looking & $79(28.4)$ & $167(60.1)$ & $32(11.5$ \\
\hline 11. & Females prefer males having good job or sound economic background & $215(77.4)$ & $52(18.7)$ & $11(4.0)$ \\
\hline
\end{tabular}

Source: Field Survey, 2015.

Table 1: Perception of sampled respondents about physical characteristics of mate. 
Citation: Sarir S, Muhammad N, Ala I, Jadoo MA, Iqbal S, et al. (2018) Role of Physical Attractiveness in Mate Selection by Educated Women in Khyber Pakhtunkhwa. Arts Social Sci J 9: 335. doi: 10.4172/2151-6200.1000335

Page 3 of 4

physical characteristics statements that females, nowadays, prefer welldressed $(p=0.000)$, broad shouldered $(p=0.000)$, clean shaved $(p=0.000)$ and fair color males $(\mathrm{p}=0.013)$. However, a non-significant association was found regarding the statements stating that beauty is a relative term $(\mathrm{p}=0.952)$, males personality traits are important in mate selection process $(\mathrm{p}=0.464)$. The results are in line with the findings of previous studies [8-14]. They found physical attractiveness as a whole was the major consideration of both the males and females in mate selection. The tendency was more among males while females were also interested in other features of males besides physical.

On the other hand, the respondents at the same time were found less concerned with the physical characteristics of males through validating the statements describing that females prefer intelligent males $(\mathrm{p}=0.000)$. They were also willing to marry men who were not good looking $(\mathrm{p}=0.007)$. The statement describing physical structure of males are less important was non-significant $(\mathrm{p}=0.076)$. The same was reported by Buunk et al,Sprecher and Reagan and Kurzban and Weeden who report that only men exhibit a preference for physical attractiveness while women are more prone to intelligence and race. Emotional stability, good job, sound economic background, kindness, understanding, openness etc. were the other features women want to see in potential mate of life $[15,18,19]$

The table as a whole reports physical characteristics as importance consideration for in mate selection. At the same time, the sampled females gave more weight to other characteristics of the males such as intelligence, higher socioeconomic status and good job (Table 2).

\begin{tabular}{|c|c|c|c|c|c|}
\hline \multirow[t]{2}{*}{ S. No. } & \multirow[t]{2}{*}{ Physical Characteristics } & \multicolumn{3}{|c|}{ Mate Selection } & \multirow[t]{2}{*}{ Chi- Square $P=$ Value } \\
\hline & & Yes & No & Uncertain & \\
\hline \multirow[t]{4}{*}{1.} & \multicolumn{5}{|c|}{ Beauty is a relative term and varies from person to person } \\
\hline & Yes & $127(45.7)$ & $102(36.7)$ & $2(0.71)$ & \multirow[t]{3}{*}{$0.694(p=0.952)$} \\
\hline & No & $18(6.5)$ & $16(5.8)$ & $0(0)$ & \\
\hline & Uncertain & $8(2.9)$ & $5(1.8)$ & $0(0)$ & \\
\hline \multirow[t]{4}{*}{2.} & \multicolumn{5}{|c|}{ Males personality traits are important elements in mate selection } \\
\hline & Yes & $131(47.1)$ & $98(35.3)$ & $2(0.7)$ & \multirow[t]{3}{*}{$3.589(p=0.464)$} \\
\hline & No & $19(6.8)$ & $18(6.5)$ & $0(0.0)$ & \\
\hline & Uncertain & $3(1.1)$ & $7(2.5)$ & $0(0.0)$ & \\
\hline \multirow[t]{4}{*}{3.} & \multicolumn{4}{|c|}{ Females nowadays prefer well-dressed males } & \\
\hline & Yes & $121(43.5)$ & $77(27.7)$ & $2(0.7)$ & \multirow[t]{3}{*}{$20.228(p=0.000)$} \\
\hline & No & $25(9.0)$ & $19(6.8)$ & $0(0.0)$ & \\
\hline & Uncertain & $7(2.5)$ & $27(9.7)$ & $0(0.0)$ & \\
\hline \multirow[t]{4}{*}{4.} & \multicolumn{5}{|l|}{ You prefer tall and broad shoulder males } \\
\hline & Yes & $100(36.0)$ & $71(25.5)$ & $2(0.7)$ & \multirow[t]{3}{*}{$20.744(p=0.000)$} \\
\hline & No & $45(16.2)$ & $24(8.6)$ & $0(0.0)$ & \\
\hline & Uncertain & $8(2.9)$ & $28(10.1)$ & $0(0.0)$ & \\
\hline \multirow[t]{4}{*}{5.} & \multicolumn{4}{|c|}{ Your mate should at least be good looking } & \\
\hline & Yes & $153(55.0)$ & $123(44.2)$ & $2(0.7)$ & \multirow[t]{3}{*}{$8.041(p=0.090)$} \\
\hline & No & $130(46.8)$ & $88(31.7)$ & $2(0.7)$ & \\
\hline & Uncertain & $15(5.4)$ & $24(8.6)$ & $0(0.0)$ & \\
\hline \multirow[t]{4}{*}{6.} & \multicolumn{4}{|c|}{ Physical features of males nowadays are less important } & \\
\hline & Yes & $74(26.6)$ & $42(15.1)$ & $0(0.0)$ & \multirow[t]{3}{*}{$8.460(p=0.076)$} \\
\hline & No & $13(4.7)$ & $17(6.1)$ & $0(0.0)$ & \\
\hline & Uncertain & $153(55.0)$ & $123(44.2)$ & $2(0.7)$ & \\
\hline \multirow[t]{4}{*}{7.} & You like to marry a male having a cle & & & & \\
\hline & Yes & $73(26.3)$ & $38(13.7)$ & $2(0.7)$ & $44.780(p=0.000)$ \\
\hline & No & $68(24.5)$ & $37(13.3)$ & $0(0.0)$ & \\
\hline & Uncertain & $12(4.4)$ & $48(17.3)$ & $0(0.0)$ & \\
\hline 8. & You prefer fair color males & & & & \\
\hline & Yes & $78(28.1)$ & $52(18.7)$ & $2(0.7)$ & $12.740(p=0.013)$ \\
\hline & No & $64(23.0)$ & $46(16.5)$ & $0(0.0)$ & \\
\hline & Uncertain & $11(4.0)$ & $25(9.0)$ & $0(0.0)$ & \\
\hline 9. & You prefer male's intelligence beyond & ctiveness & & & \\
\hline & Yes & $114(41.0)$ & $71(25.5)$ & $0(0.0)$ & $69.597(p=0.000)$ \\
\hline & No & $35(12.6)$ & $49(17.6)$ & $0(0.0)$ & \\
\hline & Uncertain & $4(1.4)$ & $3(1.1)$ & $2(0.7)$ & \\
\hline 10. & You are willing to marry a male who is & & & & \\
\hline & Yes & $153(55.0)$ & $123(44.2)$ & $2(0.7)$ & $14.247(p=0.007)$ \\
\hline & No & $56(20.1)$ & $23(8.3)$ & $0(0.0)$ & \\
\hline & Uncertain & $85(30.6)$ & $80(28.8)$ & $2(0.7)$ & \\
\hline 11. & Females prefer males having good jo & mic backgro & & & \\
\hline & Yes & $153(55.0)$ & $123(44.2)$ & $2(0.7)$ & $46.570(P=0.000)$ \\
\hline & No & $139(50.0)$ & $75(27.0)$ & $0(0.0)$ & \\
\hline & Uncertain & $9(3.2)$ & $41(14.7)$ & $2(0.7)$ & \\
\hline
\end{tabular}

Source: Field Survey 2015

Table 2: Association between physical characteristics and mate selection. 
Citation: Sarir S, Muhammad N, Ala I, Jadoo MA, Iqbal S, et al. (2018) Role of Physical Attractiveness in Mate Selection by Educated Women in Khyber Pakhtunkhwa. Arts Social Sci J 9: 335. doi: 10.4172/2151-6200.1000335

\section{Conclusion and Recommendations}

Mate selection is an important step towards formation of a family. A sound footing of both the marriage and family depend on selecting an appropriate mate for both males and females. The study as a whole found a contradiction in the perception of females for selecting a potential life partner. Like other societies, physical characteristics or attractiveness was main priority of the females and they preferred good looking, well dressed, tall, broad shouldered fair colored and clean shaved males. At the same time, they also wanted to get marry with economically sound person, who should be intelligent, and have good job. This was attributed to their education and urbanized values giving more importance to western values and monetary gains along with current price hike and social status based on wealth in the society. The other major reason was change in mate selection decision from the family to the concerned individuals who were predominantly more prone to materialism and had lessor beliefs and knowledge of religion Islam. It also showed the maturity and pragmatic approach of the females due to outside exposure because of their education and practical experience. Such type of thinking had also resulted delay in marriage, marriage age and separation or divorce after marriage. The study recommends to make balance between modern value and current trend with religious and cultural value by making mate selection decisions in a more pragmatic way by keeping all the options and situations in mind. It can be achieved through a campaign by involving all media sources and stakeholders.

\section{References}

1. Roberts BD (1994) Lifespan Development.

2. Islam S (1992) A Sociological Study of Factors Effecting the Marital Adjustment of Couples in Selected Community of Faisalabad District MSc Un-published Thesis Faisalabad (Pakistan): University of Agriculture Department of Rural Sociology.

3. Frank N, Gill M (2002) International Encyclopedia of Sociology, (Delgada HL) British Library.

4. Rehman SY (2002) Sociology the Basic Concepts Faisalabad (Pakistan) Allied Publishers.

5. Chaudhry S (2004) The Investigation into Attitude of Rural Women towards Exchange Marriages: A Case Study in District Jhang (Doctoral dissertation MSc Thesis Rural Sociology Univ of Agric Faisalabad).

6. Barbara A, David EK (1989) Marriage Across Frontiers Philadelphia: Multilingual Matters Ltd.

7. Gulzar A, Husain W (2015) The Psychosocial Preferences in Mate Selection among Pakistanis FWU. Journal of Social Sciences 9: 29.

8. Franklin RG, Adams RB (2009) A dual-process account of female facial attractiveness preferences: Sexual and nonsexual routes. Journal of Experimental Social Psychology 45: 1156-1159.

9. Perilloux C, Fleischman DS, Buss DM (2011) Meet the Parents: ParentOffspring Convergence and Divergence in Mate Preferences Personality and Individual Differences 50: 253-258.
10. Bronstad PM, Russell R (2007) Beauty is in the 'we' of the beholder: Greater agreement on facial attractiveness among close relations Perception Vol-36.

11. Rhodes G (2006) The evolutionary psychology of facial beauty Annu Rev Psychol 57: 199-226.

12. Winkielman P, Halberstadt J, Fazendeiro T, Catty S (2006) Prototypes Are Attractive Because They Are Easy on the Mind Psychological science 17: 799-806.

13. Hoppe HC, Moldovanu B, Sela A (2009) The Theory of Assortative Matching Based on Costly Signals The Review of Economic Studies 76: 253-281.

14. Fisman R, lyengar SS, Kamenica E, Simonson I (2006) Gender differences in mate selection: Evidence from a speed dating experiment The Quarterly. Journal of Economics pp: 673-697.

15. Kurzban R, Weeden J (2005) HurryDate: Mate Preferences in Action Evolution and Human Behavior 26: 227-244.

16. Belot M, Francesconi M (2006) Can Anyone Be "The" One? Evidence on Mate Selection from Speed Dating IZA DP No 2377 For schungs institutzurZukunf der Arbeit Institute for the Study of Labor.

17. Berry DS, Miller KM (2001) When boy meets girl: Attractiveness and the fivefactor model in opposite-sex interactionazs. Journal of Research in Personality 35: 62-77.

18. Buunk BP, Dijkstra P, Fetchenhauer D, Kenrick DT (2002) Age and gende differences in mate selection criteria for various involvement levels. Persona Relationships 9: 271-278.

19. Sprecher S, Regan PC (2002) Liking Some Things (In Some People) More Than Others: Partner Preferences in Romantic Relationships and Friendships. Journal of Social and Personal Relationships 19: 463-481.

20. Hatfield E, Sprecher S (1995) Men's and Women's Preferences in Marital Partners in The United States Russia and Japan. Journal of Cross-Cultura Psychology 26: 728-750.

21. Sekaran U (2003) Research Methods for Business USA Hermitage Publishing Service.

22. Buss DM (2003) The Evolution of Desire: Strategies of Human Mating Basic books.

23. Buss DM, Barnes M (1986) Preferences in human mate selection. Journal of Personality and Social Psychology 50: 559.

24. Kalmijn M, Flap H (2001) Assortative Meeting and Mating: Unintended Consequences of Organized Settings for Partner Choices Social forces 79 1289-1312.

25. Gage J, Hancock D (2007) Where is the Money Honey: The Socioeconomic Effects of Mate Choice?

26. Todosijević B, Ljubinković S, Arančić A (2003) Mate Selection Criteria: A Trait Desirability Assessment Study of Sex Differences in Serbia Evolutionary Psychology Vol-1.

27. Koehler N (2005) Characteristics and Impression Formation in Marriage Choice. Journal of Social Psychology 72: 730-738.

28. Kenrick DT, Groth GE, Trost MR, Sadalla EK (1993) Integrating Evolutionary and Social Exchange Perspectives on Relationships: Effects of Gender Self-Appraisal and Involvement Level on Mate Selection Criteria. Journal of Personality and Social Psychology 64: 951-969. 